\title{
Investigation of Dielectric Properties of Industrial Waste Reinforced Particulate Polymer Composites
}

\author{
Vijaya Kumar Nimmagadda, ${ }^{1}$ M. M. M. Sarcar, ${ }^{2}$ and Ramji Koona ${ }^{2}$ \\ ${ }^{1}$ Department of Mechanical Engineering, V. R. Siddhartha Engineering College, Vijayawada 520007, India \\ ${ }^{2}$ Department of Mechanical Engineering, College of Engineering, Andhra University, Visakhapatnam 530003, India \\ Correspondence should be addressed to Vijaya Kumar Nimmagadda; vknimmagadda@rediffmail.com
}

Received 28 May 2013; Accepted 25 October 2013; Published 3 February 2014

Academic Editor: Luigi Nicolais

Copyright ( 2014 Vijaya Kumar Nimmagadda et al. This is an open access article distributed under the Creative Commons Attribution License, which permits unrestricted use, distribution, and reproduction in any medium, provided the original work is properly cited.

\begin{abstract}
Environmental awareness today motivates the worldwide researchers on the studies of industrial waste reinforced polymer composites. Rapid industrialization has resulted in the generation of huge quantity of solid and liquid wastes such as sugar, paper and pulp, fruit and food processing, distilleries, dairies, and poultries. The redundancy of industrial waste and government regulations have prompted researchers to try for industrial waste reinforced composites. Being low cost, ease of manufacturing, and high mechanical and other properties, an industrial waste represents a good alternative to the most common composites. In the present study, industrial wastes collected from different industries are used as particulate reinforcement in unsaturated polyester matrix and also in polypropylene and investigated dielectric properties. Results reveal that coupling agent treated composites produce improved dielectric strength due to improvement in compatibility between matrix and reinforcement interface. Results also reveal that industrial waste reinforced in polypropylene has more dielectric strength as compared to reinforcement in polyester.
\end{abstract}

\section{Introduction}

In the recent past, polymers have been playing an important role in composites. Due to paucity of metals, many scientists are looking for new and alternative metals. Composites are attractive due to their low cost, easy fabrication, good mechanical properties, and so forth. Among those alternatives unsaturated polyester is attractive due to its dimensional stability, low price, and light weight [1]. It belongs to the thermosetting group of polymers. They offer exciting advantages from the view point of their wide spread applications $[2,3]$.

Fiber reinforced composites are the most attractive composites. Both synthetic and natural fibers are reinforced in polymers and investigate mechanical, electrical and thermal properties by different researchers [4-7]. Jute fiber reinforced polypropylene composites prepared by injection moulding method has been investigated and reported as posttreated specimens yielded better mechanical results compared to raw ones $[8,9]$.

Due to industrialization enormous amount of waste develops. Producing more products results in more waste production. It will be dumped on land side as land fill or simply piled up damaging ecological balance. Government regulations and ecoconsciousness force the public to look for alternative methods to use these wastes. Tire dust being produced during tire milling has been used as reinforcement in HDPE thermoplastic and investigated the electrical, mechanical, and thermal properties [10]. Fly ash is an industrial waste being used for reinforcement in thermoplastics and thermosetting by many researchers. Reports reveal that fly ash improves mechanical, thermal, and electrical properties [11, 12]. Effect of fly ash fraction on mechanical properties of unsaturated polyester composites is investigated as reported in [13]. Impact properties and addition of silane on fly ash reinforced epoxy is also investigated and reported improvement in energy absorption with the addition of silane coupling agent [14]. Red mud was the caustic insoluble waste residue, generated by alumina production from bauxite by the Bayer's process. Red mud is used as filler in metal matrix composites and polymer composites [15-17]. Paper waste is another industrial waste produced while manufacturing paper. This waste is used as reinforcing agent in polymer 
composites $[18,19]$. Flue dust is an industrial waste reinforced in unsaturated polyester and investigated coefficient of friction and wear loss [20] Chicken feather also a waste from poultry is reinforced in epoxy matrix composite [21]. It is found that dielectric properties are dependent on temperature and frequency range.

The major drawback observed is the interaction and compatibility between reinforcement and the matrix. To over come this, different coupling agents are used. Silane is the most commonly used coupling agent by many researchers. Kraft and Sisal fibers are used as reinforcement in polylactic acid and are investigated for mechanical and thermal properties [22]. He concluded that the mechanical properties were improved where there was no significant change in thermal properties. Properties are improved further and the microscopic analysis reveals good dispersion of reinforcement with the addition of silane. Silane addition on wood flour reinforced polypropylene composite improved the tensile, flexural, impact properties of the composites [23].

Particulate reinforced composites are very attractive due to the ease of manufacturing and mouldability. Aluminium particles are reinforced in epoxy resin and are investigated for their dielectric properties with and without coupling agents [24]. Dielectric properties are improved further with the addition of coupling agent at higher loading due to proper dispersion of particles in the resin. Flue dust is reinforced in polyester and its dielectric properties are investigated [25]. Dielectric strength increases with the addition of silane due to improved bonding between organic matrix and inorganic industrial waste.

\section{Experimentation}

\subsection{Materials Used}

2.1.1. Materials (Polyester). In the present study, a commercially available unsaturated polyester resin ECMALON 4413 grade procured from ECMAS Resins Pvt. Ltd, Hyderabad, India, has been used as the matrix material for composite preparation. Cobalt accelerator of about $2 \%$ and $2 \%$ methyl ethyl ketone peroxide (MEKP) hardener are added. For modifying the industrial waste powder Silane (glycidoxy propyl trimethoxysilane), the coupling agent is used. It is procured from Sree Industrial Composite Products, Hyderabad, India. Silica fume powder is procured from Navabharat Ferro alloys, Paloncha, India. Sludge, slag, and flue dust have been collected from Lanco industries, Srikahasthi, India. Granite is collected from Visakhapatnam, India. All the materials are cleaned thoroughly with water and dried in an oven.

2.1.2. Materials (Polypropylene). Polypropylene procured from Reliance industries Pvt. Ltd, India, has been used as the matrix material for composite preparation.

\subsection{Sample Preparation}

2.2.1. Sample Preparation (Polyester). The cavity for testing dielectric strength is made as per ASTM D-149 standards on

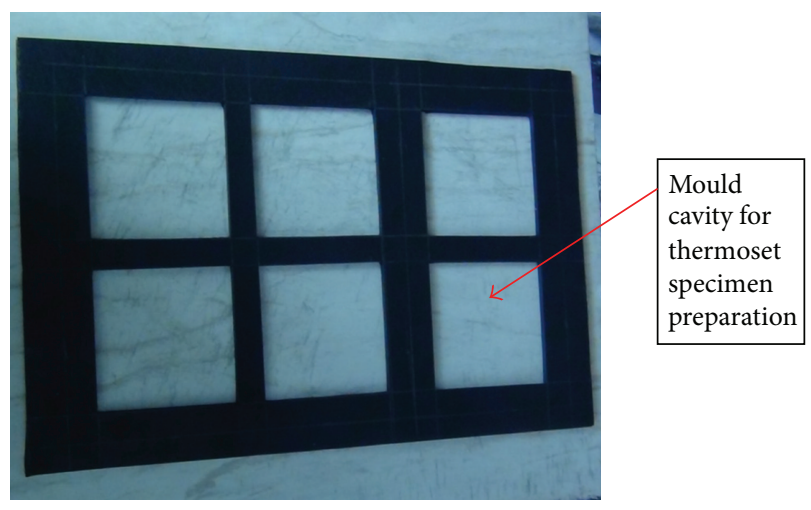

FIGURE 1: Mould prepared on rubber shoe as per ASTM D-149.

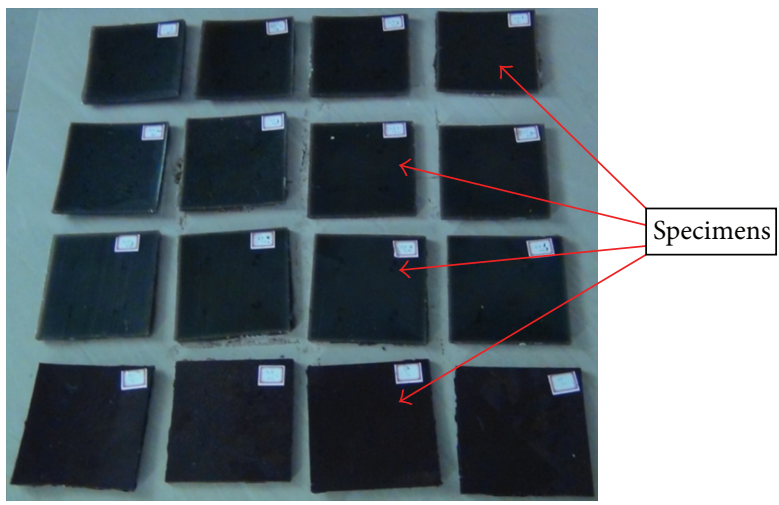

FIGURE 2: Specimens of different industrial waste material.

a rubber shoe as shown in Figure 1. Industrial wastes of $0-$ $40 \mu \mathrm{m}$ size are thoroughly mixed in proper ratio $(0,10,20$, 30,45 , and $60 \%$ ) by weight with the resin and others for preparing composite specimens. Hand layup technique has been used for preparing specimens. The mould is coated with uniform thin film of silicon-releasing agent for easy removal of specimens from the mould after curing. The samples are cured at room temperature for about $24 \mathrm{hrs}$ and then they are removed from the mould and finished to the size by filing the edges as shown in Figure 2. For each composition three specimens are prepared and each specimen is tested at 4 different places on the specimen. Specimens are also prepared by adding silane at 0.3 and $0.5 \%$ by hand layup process. A simplified approach of simply adding silane during the dispersion of particles is used for surface treatment.

2.2.2. Sample Preparation (Polypropylene). The composite samples are also prepared using polypropylene as matrix material. The matrix material pallets are mixed with industrial wastes of 0 to $40 \mu \mathrm{m}$ size in proper ratio $(0,10,20,30,45$, and $60 \%$ ). The mixture is then placed in a 2.5 ton hydraulic injection moulding machine, model JIM-1 supplied by Texier plastics limited, Coimbatore, India. $1100 \mathrm{Kgf}$ pressure is applied at $210^{\circ} \mathrm{C}$ for manufacturing specimens. 


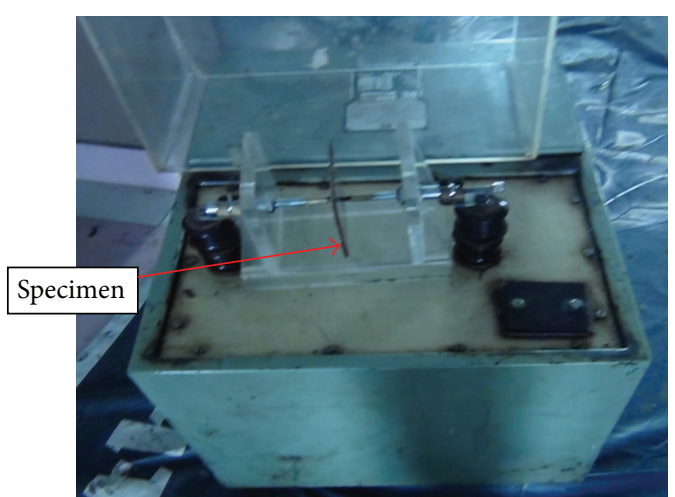

FIGURE 3: Dielectric strength machine with specimen.

\subsection{Test}

2.3.1. Test Equipment. The dielectric test equipment having output voltage sample $0-60 \mathrm{KV}$, capacity $100 \mathrm{ma}$, and rating 15 minutes ON/OFF was supplied by rectifiers IE electronics, New Delhi, as shown in Figure 3. It has motorized (variable rate of rise of voltage) control. High voltage transformer was cooled with transformer oil of $100 \mathrm{KV}$ capacity and the control Panel was cooled by circulation of air. The equipment is having a least count of $0.5 \mathrm{KV}$ and is provided with stepwise of electric strength at the electrodes. The equipment facilitates to find die-electric strength of plastics, composite, insulating rubber, and other solid insulating materials as per the ASTM standard test method D149-87. The equipment also provided with different types of electrodes used to find the die-electric breakdown voltages and die-electric strength of solid electrical insulating materials of commercial power frequencies.

2.3.2. Testing. The standards specified by ASTM have been used in present analysis. The initial voltage is selected as $20 \mathrm{KV}$, since the specimen breakdown voltage under the short time test is found to be about $40 \mathrm{KV}$. The initial voltage is increased rapidly from zero. The breakdown voltage is held for 60 seconds at every step of $1 \mathrm{KV}$ rise. The dielectric breakdown voltage is performed on each specimen at different points and the average value is considered for the analysis. The test is carried out at $50 \mathrm{~Hz}$ frequency and at normal temperature and pressure. Digital micrometer with $0.001 \mathrm{~mm}$ least count is used for measuring the thickness of the specimen at breakdown point prior to the test. Dielectric strength is calculated by dividing the breakdown voltage at that particular point by the thickness of the sample at the same point.

\section{Results and Discussions}

Figure 4 shows dielectric strength of sludge reinforced composite. It is observed that dielectric strength decreases with the addition of sludge up to $30 \%$ due to conductivity of the reinforcement. Further increase of sludge increases the dielectric strength. The coupling agent silane modified

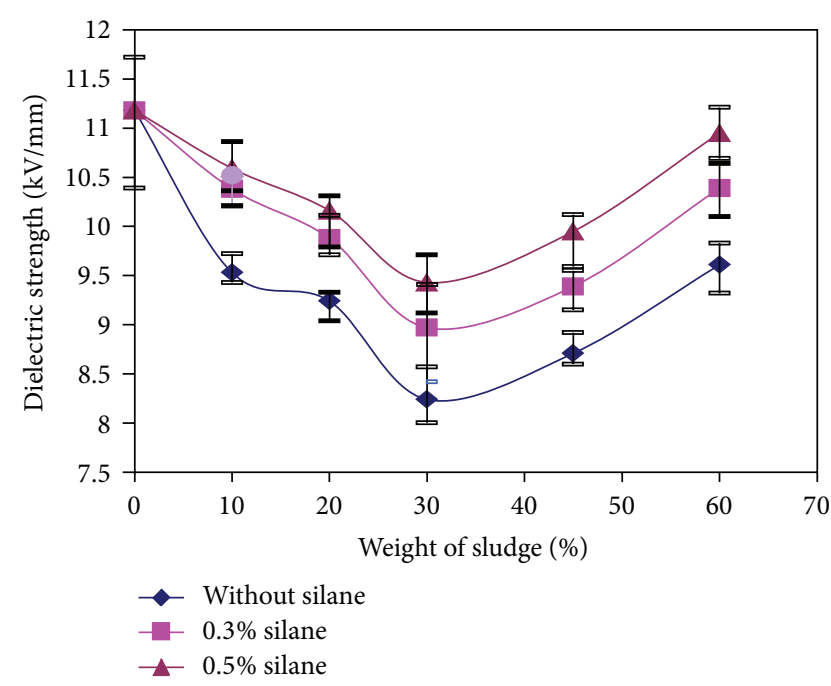

FIGURE 4: Dielectric strength of sludge reinforced polyester composites with and without silane.

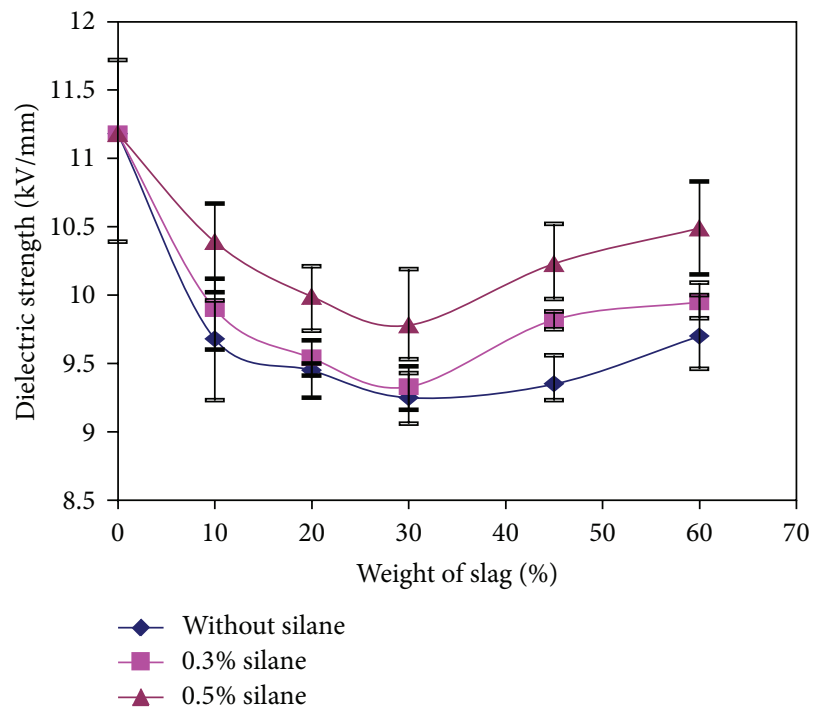

FIGURE 5: Dielectric strength of slag reinforced polyester composites with and without silane.

the property of sludge reinforced composite that shows higher dielectric strength due to more compatibility between sludge and coupling agent. Figure 5 shows dielectric strength of slag reinforced composite. Addition of slag reduces the dielectric strength to $9.68 \mathrm{Kv} / \mathrm{mm}$ from $11.18 \mathrm{Kv} / \mathrm{mm}$ at $10 \%$. There is not much variation from $10 \%$ to $30 \%$. Further addition of slag increases the dielectric strength. There is not much change with the addition of $0.3 \%$ silane to slag at lower loadings upto $30 \%$. But with the addition of $0.5 \%$ silane dielectric strength improves.

Figure 6 shows dielectric strength of granite reinforced composite. The variation of dielectric strength is very low at $10 \%$ as compared to pure specimen. The dielectric strength reduces upto $30 \%$ and then increases, but the variation is less. It is observed that the $10 \%$ granite reinforced with $0.5 \%$ silane 


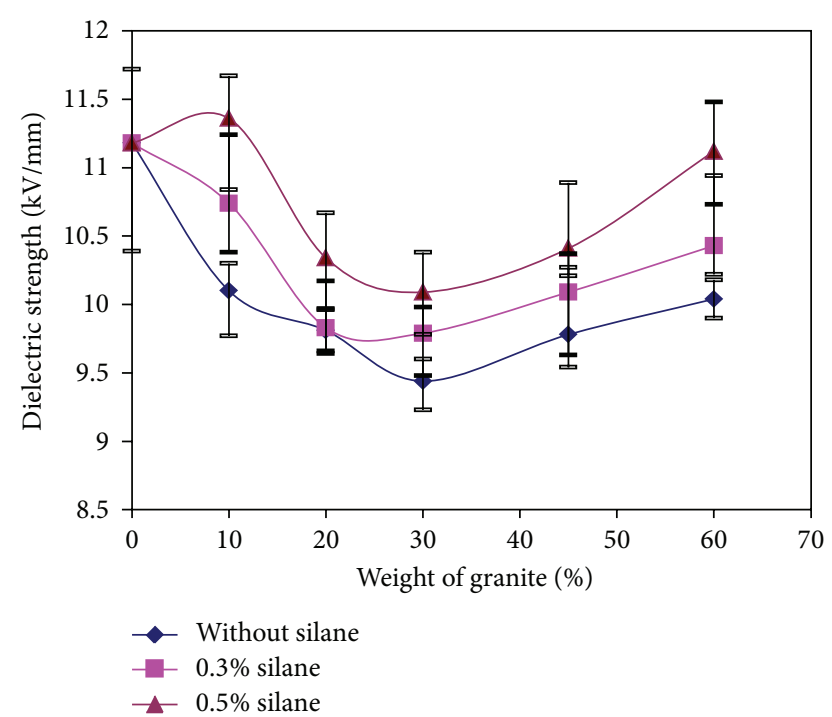

FIGURE 6: Dielectric strength of granite reinforced polyester composites with and without silane.

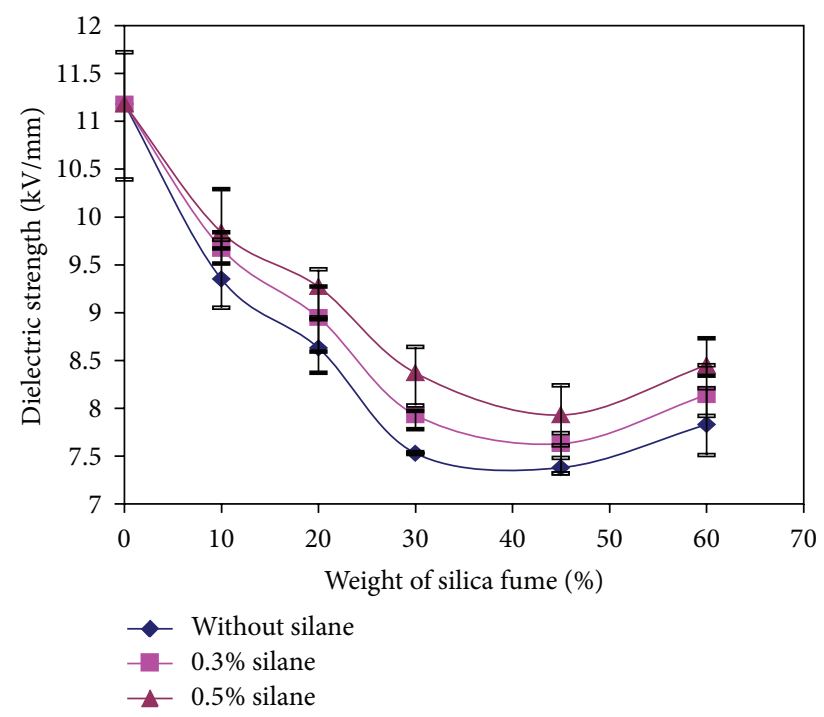

FIGURE 7: Dielectric strength of silica fume reinforced polyester composites with and without silane.

coupling agent produces dielectric strength more than that of pure specimen and $60 \%$ granite with $0.5 \%$ silane reinforced produces almost same as pure one.

Dielectric strength of silica fume reinforced composite is shown in Figure 7. Dielectric strength reduces upto $45 \%$ of loading, further addition of silica fume dielectric strength increases. Addition of silane shows similar trend with improved strength. In all the cases, addition of silane increases dielectric strength due to improved bonding between inorganic reinforcement and organic matrix.

Figure 8 represents dielectric strength of different reinforcing materials without coupling agent. There is a significant change in dielectric strength of silica fume at $10 \%$ of loading as compared to pure resin and this change is

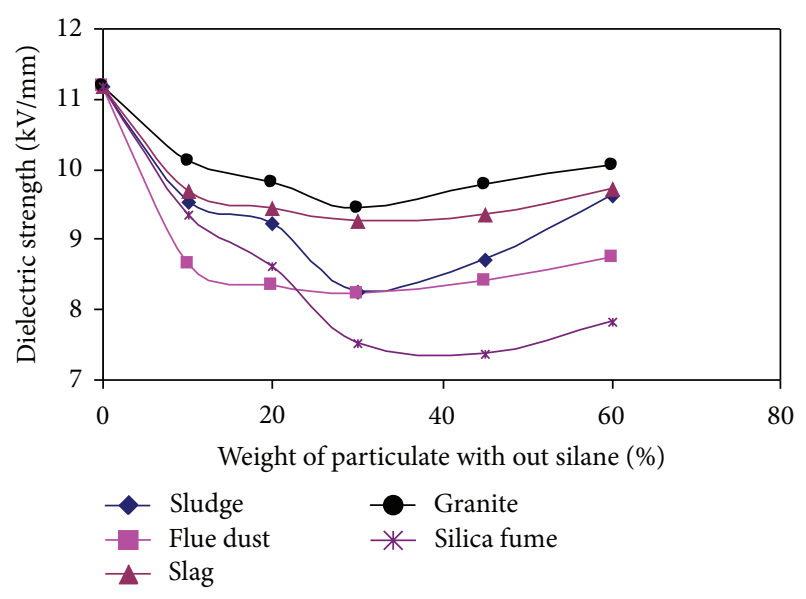

FIGURE 8: Dielectric strength of waste reinforced polyester composites without silane.

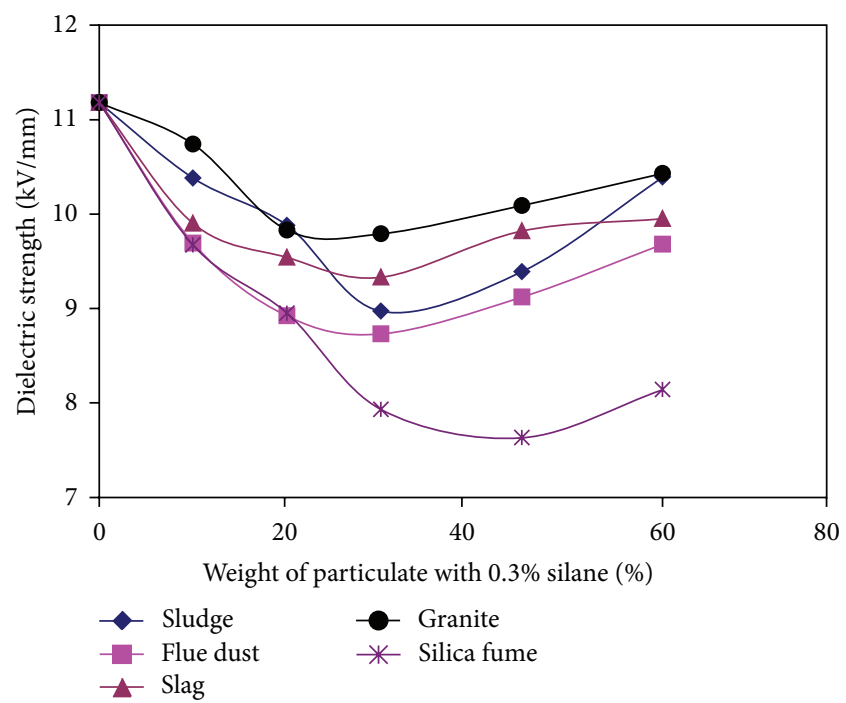

FIGURE 9: Dielectric strength of waste reinforced polyester composites with $0.3 \%$ silane.

not much with further addition of flue dust. Dielectric strength of silica fume reduced steadily to $7.38 \mathrm{Kv} / \mathrm{mm}$ at $45 \%$ of reinforcement. Further addition of silica fume dielectric strength increases. With the other materials dielectric strength reduces upto $30 \%$ of reinforcement steadily at lower rate and then increases. Figures 9 and 10 represent dielectric strength of materials with $0.3 \%$ and $0.5 \%$ silane coupling agent, respectively. With the addition of $0.5 \%$ silane, $10 \%$ granite produces dielectric strength higher than pure resin. Hence it can be used as packing material to reduce the cost of packing.

Figure 11 represents dielectric strength of industrial waste reinforced polypropylene composites. It shows that the dielectric strength reduces with the addition of reinforcement upto $30 \%$. Further addition of reinforcement increases the dielectric strength. However dielectric strength of silica fume reduces upto $45 \%$ of reinforcement. It is observed that the silica fume may be used as conducting material with $45 \%$ 
TABLE 1: Comparison of dielectric strength of industrial wastes reinforced in unsaturated polyester and polypropylene.

\begin{tabular}{lcccccccccc}
\hline & \multicolumn{4}{c}{ Unsaturated polyester without silane } & \multicolumn{4}{c}{ Polypropylene } \\
& Sludge & Flue dust & Slag & Granite & Silica fume & Sludge & Flue dust & Slag & Granite & Silica fume \\
\hline $0 \%$ & 11.18 & 11.18 & 11.18 & 11.18 & 11.18 & 13.07 & 13.07 & 13.07 & 13.07 & 13.07 \\
$10 \%$ & 9.53 & 8.65 & 9.68 & 10.1 & 9.35 & 11.54 & 12.02 & 12.31 & 12.06 & 11.75 \\
$20 \%$ & 9.24 & 8.34 & 9.45 & 9.81 & 8.63 & 10.65 & 11.05 & 11.5 & 11.21 & 10.7 \\
$30 \%$ & 8.24 & 8.23 & 9.25 & 9.44 & 7.53 & 10.19 & 10.38 & 10.8 & 10.89 & 9.98 \\
$45 \%$ & 8.71 & 8.41 & 9.35 & 9.78 & 7.38 & 10.59 & 11.28 & 11.61 & 12.03 & 9.88 \\
$60 \%$ & 9.61 & 8.73 & 9.7 & 10.04 & 7.83 & 11.79 & 12.42 & 12.68 & 13.13 & 10.62 \\
\hline
\end{tabular}

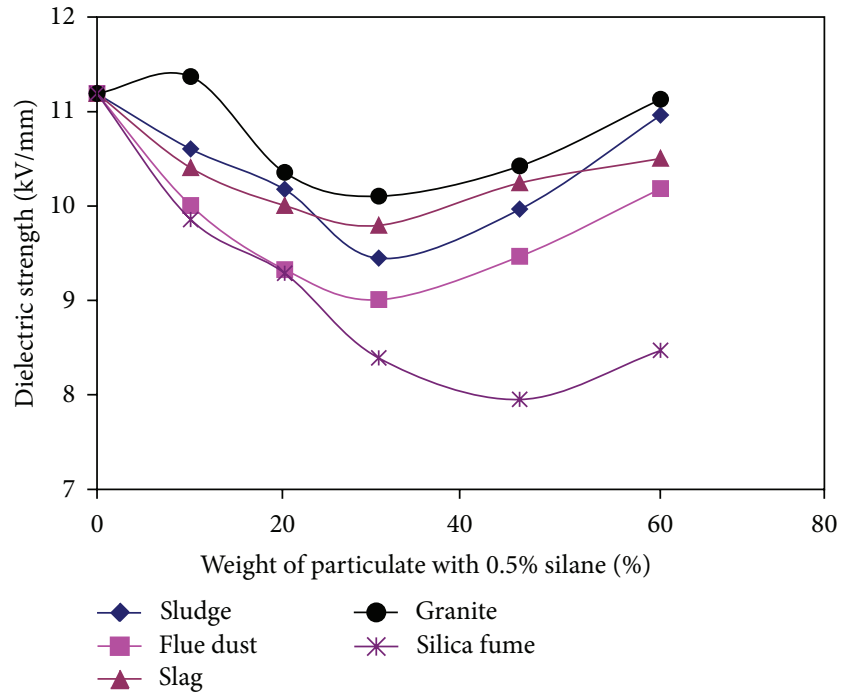

FIGURE 10: Dielectric strength of waste reinforced polyester composites with $0.5 \%$ silane.

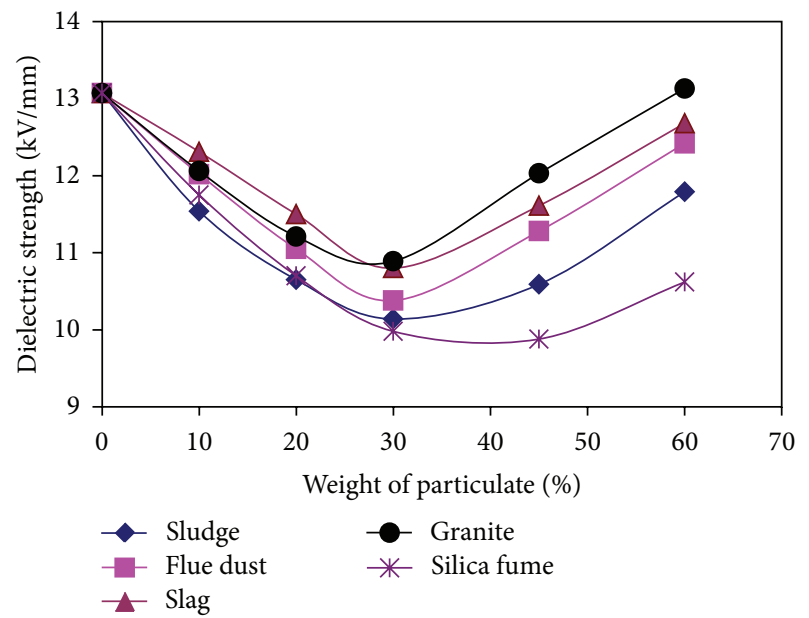

FIGURE 11: Dielectric strength of waste reinforced polypropylene composites.

of reinforcement. Granite with $60 \%$ by weight reinforced in polypropylene produces dielectric strength higher than pure polypropylene. Table 1 represents dielectric strength of industrial wastes reinforced in unsaturated polyester and polypropylene. It gives clear idea that industrial wastes reinforced in polypropylene produce higher dielectric strength compared to unsaturated polyester.

\section{Conclusion}

Based on the experimental analysis, following conclusions have been drawn.

(i) Industrial waste can be gainfully reinforced into the unsaturated polyester and polypropylene.

(ii) Composites can easily be made by hand layup technique.

(iii) By incorporating industrial wastes as reinforcement in to the polyester, it can be used in electrical parts where plastic is used.

(iv) Dielectric strength of silica fume is 33.99\% lower than pure polyester. Hence it can be used in electrical parts to reduce the cost of resin.

(v) Dielectric strength improves with the addition of silane.

(vi) $10 \%$ granite reinforced in polyester with $0.5 \%$ silane composites produces dielectric strength $12.5 \%$ higher than without silane and $1.6 \%$ higher than pure polyester.

(vii) Composites with polypropylene matrix have $16.9 \%$ higher dielectric strength compared to unsaturated polyester matrix composites.

(viii) Granite (60\%) reinforced in polypropylene produces dielectric strength $0.5 \%$ higher than pure polypropylene. Hence it can be used as packing material to reduce the cost of resin.

\section{Conflict of Interests}

The authors declare that there is no conflict of interests regarding the publication of this paper.

\section{References}

[1] E. A. Osman, A. Vakhguelt, I. Sbarski, and A. Saad Mutasher, "Kenaf/recycled jute natural fibers unsaturated polyester composites: water absorption/dimensional stability and mechanical properties," International Journal of Computational Materials Science and Engineering, vol. 1, pp. 1-17, 2012. 
[2] H. Pihtili and N. Tosun, "Investigation of the wear behaviour of a glass-fibre-reinforced composite and plain polyester resin," Composites Science and Technology, vol. 62, no. 3, pp. 367-370, 2002.

[3] N. Chand, A. Naik, and S. Neogi, "Three-body abrasive wear of short glass fibre polyester composite," Wear, vol. 242, no. 1-2, pp. 38-46, 2000.

[4] M. Thiruchitrambalam, A. Alavudeen, A. Athijayamani, N. Venkateshwaran, and A. E. Perumal, "Improving mechanical properties of banana/kenaf polyester hybrid composites using sodium laulryl sulfate treatment," Materials Physics and Mechanics, vol. 8, no. 2, pp. 165-173, 2009.

[5] E. Sinha and S. K. Rout, "Influence of fibre-surface treatment on structural, thermal and mechanical properties of jute fibre and its composite," Bulletin of Materials Science, vol. 32, no. 1, pp. 65-76, 2009.

[6] B. Suresha, G. Chandramohan, J. N. Prakash, V. Balusamy, and K. Sankaranarayanasamy, "The role of fillers on friction and slide wear characteristics in glass-epoxy composite systems," Journal of Minerals and Materials Characterization and Engineering, vol. 5, no. 1, pp. 87-101, 2006.

[7] K. Murali Mohan Rao, K. Mohana Rao, and A. V. Ratna Prasad, "Fabrication and testing of natural fibre composites: vakka, sisal, bamboo and banana," Materials and Design, vol. 31, no. 1, pp. 508-513, 2010.

[8] M. R. Rahman, M. M. Huque, M. N. Islam, and M. Hasan, "Improvement of physico-mechanical properties of jute fiber reinforced polypropylene composites by post-treatment," Composites A, vol. 39, no. 11, pp. 1739-1747, 2008.

[9] H. Haydaruzzaman, A. H. Khan, M. A. Hossain, M. A. Khan, R. A. Khan, and M. A. Hakim, "Fabrication and characterization of jute reinforced polypropylene composite: effectiveness of coupling agents," Journal of Composite Materials, vol. 44, no. 16, pp. 1945-1963, 2010.

[10] J. Orrit-Prat, R. Mujal-Rosas, A. Rahhali, M. Marin-Genesca, X. Colom-Fajula, and J. Belana-Punseti, "Dielectric and mechanical characterization of PVC composites with ground tire rubber," Journal of Composite Materials, vol. 45, no. 11, pp. 12331243, 2011.

[11] M. R. Parvaiz, S. Mohanthy, S. K. Nayak, and P. A. Mahanwar, "Polyetherketone composites reinforced with fly ash and mica," Journal of Minerals and Materials Characterization and Engineering, vol. 9, pp. 25-41, 2010.

[12] A. Patnaik and A. Satapathy, "Erosion wear response of flyashglass fiber-polyster composites: a study using taguchi experimental design," Malaysian Polymer Journal, vol. 4, no. 2, pp. 1328, 2009.

[13] N. Chand, "SEM observation of fractured flyash-polyester composites," Journal of Materials Science Letters, vol. 7, no. 1, pp. 36-38, 1988.

[14] K. Kishore, S. M. Kulkarni, D. Sunil, and S. Sharathchandra, "Effect of surface treatment on the impact behaviour of fly-ash filled polymer composites," Polymer International, vol. 51, no. 12, pp. 1378-1384, 2002.

[15] A. Satapathy and A. Patnaik, "Analysis of dry sliding wear behavior of red mud filled polyester composites using the taguchi method," Journal of Reinforced Plastics and Composites, vol. 29, no. 19, pp. 2883-2897, 2010.

[16] A. Satapathy, S. C. Mishra, P. V. Ananthapadmanabhan, and K. P. Sreekumar, "Development of ceramic coatings using red mud, a solid waste of alumina plants," in Proceedings of the 21st International Conference on Solid Waste Technology and Management, pp. 232-240, Widener University, Chester, Pa, USA, 2006.

[17] S. K. Acharya, V. Dikshit, and P. Mishra, "Erosive wear behaviour of redmud filled metal matrix composite," Journal of Reinforced Plastics and Composites, vol. 27, no. 2, pp. 145-152, 2008.

[18] S. Salmah, H. Ismail, and A. A. Bakar, "A comparative study on the effects of paper sludge and kaolin on properties of polypropylene/ethylene propylene diene terpolymer composites," Iranian Polymer Journal, vol. 14, no. 8, pp. 705-713, 2005.

[19] J. Son, H.-S. Yang, and H.-J. Kim, "Physico-mechanical properties of paper sludge-thermoplastic polymer composites," Journal of Thermoplastic Composite Materials, vol. 17, no. 6, pp. 509522, 2004.

[20] N. Vijaya Kumar, M. M. M. Sarcar, and M. D. Inayatulla, "Evaluation of wear properties of flue dust reinforced particulate polymer composite," International Journal of Earth Sciences and Engineering, vol. 5, no. 4, pp. 931-935, 2012.

[21] S. C. Mishra and N. B. Nayak, "An investigation of dielectric properties of chicken feather reinforced epoxy matrix composite," Journal of Reinforced Plastics and Composites, vol. 29, no. 17, pp. 2691-2697, 2010.

[22] D. Gonzalez, V. Santos, and J. C. Parajo, "Silane treated lignocellulosic fibers as reinforcement material in polylactic acid biocomposites," Journal of Thermoplastic Composite Materials, 2011.

[23] T.-W. Kim, S.-Y. Lee, S.-J. Chun, G.-H. Doh, and K.-H. Paik, "Effect of silane coupling on the fundamental properties of wood flour reinforced polypropylene composites," Journal of Composite Materials, vol. 45, no. 15, pp. 1595-1605, 2011.

[24] W. Zhou and D. Yu, "Effect of coupling agents on the dielectric properties of aluminum particles reinforced epoxy resin composites," Journal of Composite Materials, vol. 45, no. 19, pp. 19811989, 2011.

[25] N. Vijaya Kumar, M. M. M. Sarcar, and G. Sunnel Kumar, "Evaluation of dielectric properties of flue dust reinforced polymer composite," International Journal of Earth Sciences and Engineering, vol. 54, pp. 943-946, 2012. 

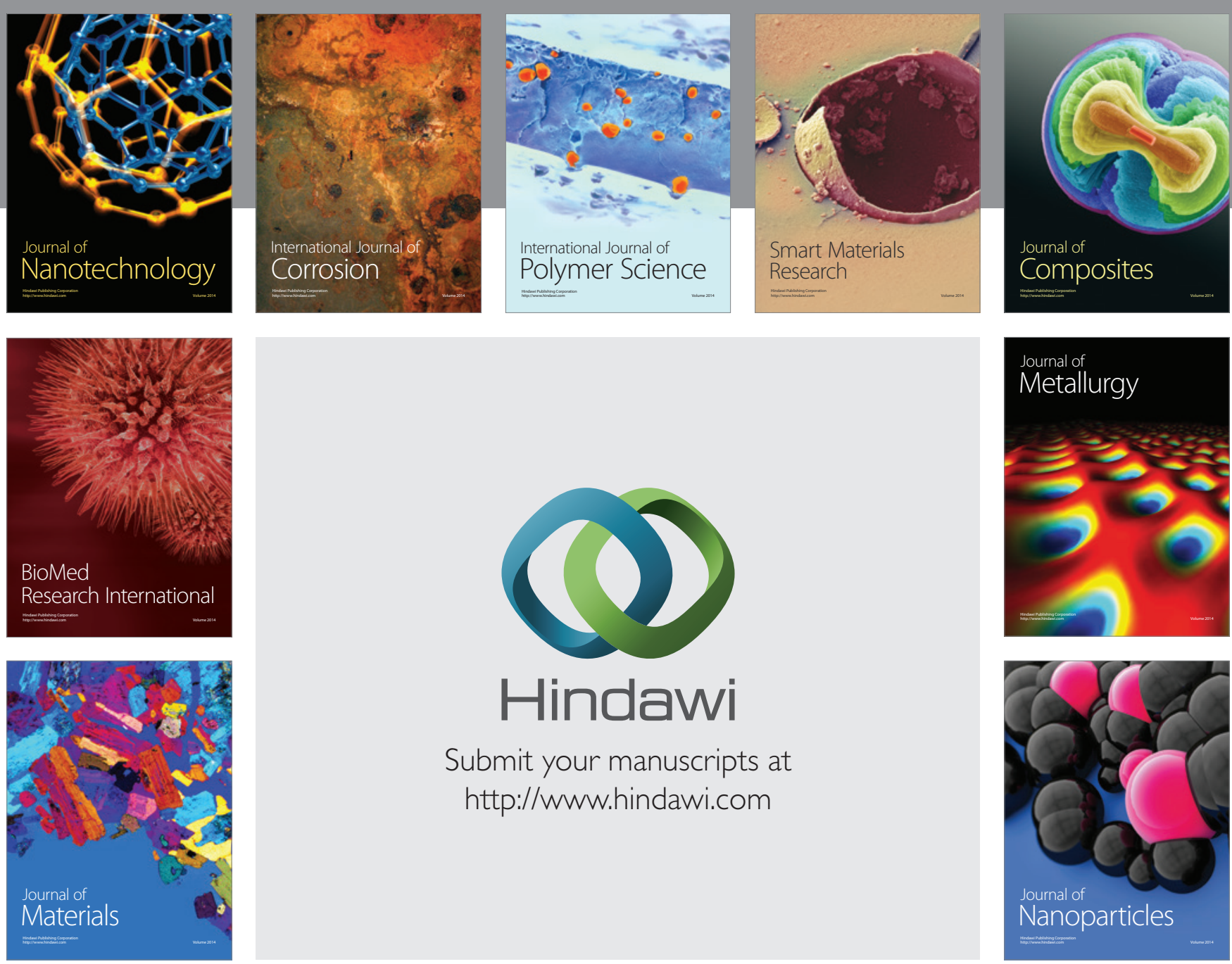

Submit your manuscripts at http://www.hindawi.com
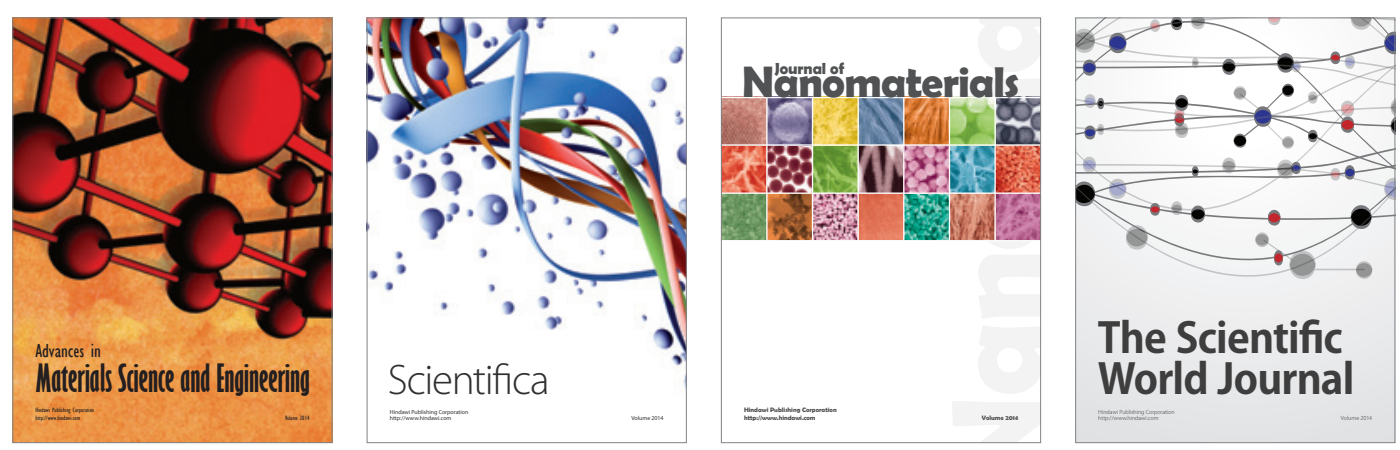

\section{The Scientific World Journal}
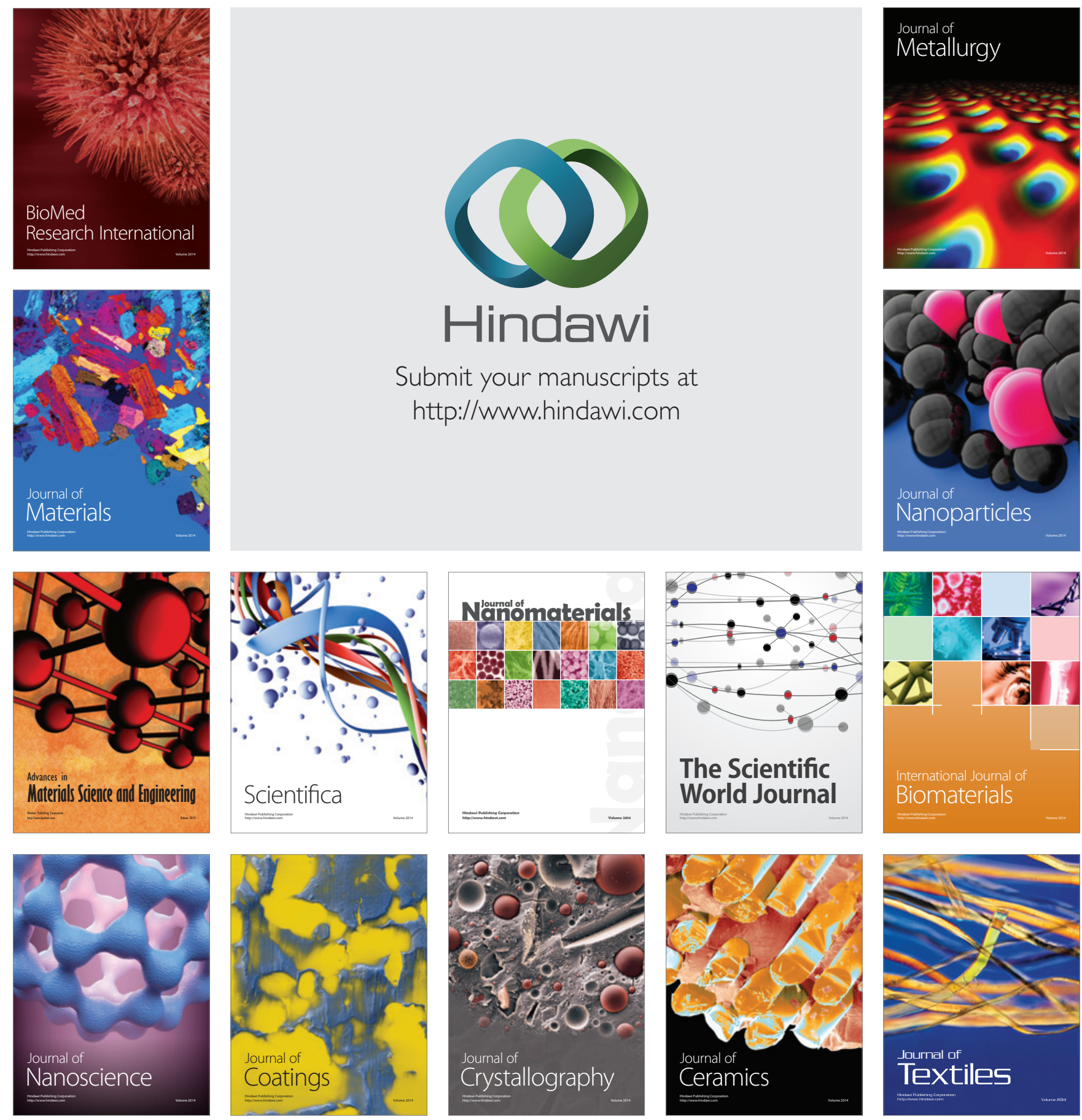